\title{
Mobile Learning in Security and Defense Organizations
}

\author{
Christian Glahn *
}

Technology has been part of education and training in security and defense organizations for a long time. E-learning and advanced distributed learning (ADL) have helped to standardize, optimize, and scale education and training. Many organizations and affiliated institutions already make good use of Web-based technologies to provide training for performance support and career development. Over the past years, ADL solutions have become part of the standard procedures of many organizations. The Partnership for Peace Consortium (PfPC) plays an important role in facilitating the exchange of knowledge and experiences among ADL practitioners in defense academies. The ADL Working Group of the PfPC is home to a strong and active community that brings new technologies into the practice of education and training in security and defense organizations. In the past, the primary focus of ADL activities was creating and enhancing interoperable Web-based training modules by promoting the adoption of the Scalable Content Object Reference Model (SCORM). The joint learning management system of the PfPC that is hosted by the International Relations and Security Network (ISN) based in Zurich has become a hub for Web-based training resources that are shared and used by the entire PfPC ADL community.

The majority of Web-based ADL systems are optimized for desktop computing, reflecting the infrastructure that is most commonly available to learners and trainers in these organizations. However, with the sophistication and widespread availability of the current generation of smartphones, mobile technologies have rapidly gained relevance on a large scale. The "mobile revolution" refers to a number of technologies that support a wider range of interaction modes beyond the "keyboard-mouse-screen" interactions that are familiar to users of desktop computers. These interaction modes include support for the "responsive" arrangement of information for a wide range of screen sizes, gesture-based touch interactions, and location-based services that go beyond active manipulation of information on a personal screen. ${ }^{1}$ These new forms of interaction are used for information filtering, but are not limited to that function. Like much other legacy information and communications technology, present ADL systems are not designed to support these new forms of interaction. Moreover, the related educational resources often appear to be unsuited for delivery to different platforms, or are not positioned to benefit from these new ways of creating, using, and sharing informa-

* Dr. Christian Glahn is a researcher for mobile learning solutions for security and defense organizations at the International Relations and Security Network, ETH Zürich, Switzerland. The research on which this article is based has been funded by the ADL Co-Lab and awarded by the Office of Naval Research Global (ONRG) under Grant No.N62909-12-1-7022. The views expressed herein are solely those of the author and do not represent or reflect the views of any academic, government or industry organization mentioned herein.

1 Ethan Marcotte, "Responsive Web Design," A List Apart (alistapart.com); available at www.alistapart.com/articles/responsive-web-design. 
tion. This raises concerns and doubts among stakeholders about the needs and benefits for supporting mobile technologies for education and training in security and defense.

In response to these socio-technological developments, a few mobile learning flagship projects have been launched in the ADL community. Until recently, these activities were only loosely connected. In order to connect the different activities and projects, the ISN Zurich organized a workshop on mobile learning in security and defense organizations in conjunction with the Eleventh World Conference on Mobile and Contextual Learning, held in Helsinki in October 2012. ${ }^{2}$ The workshop brought together researchers from these flagship projects to discuss new educational approaches, organizational constraints, standardization, and scalable solutions. The findings of the workshop provided the basis for a better understanding of the different dimensions of mobile learning in the defense sector and for improved alignment of different initiatives for mutual benefit.

The articles in this issue of Connections continue this discussion by integrating the latest results of research and development projects in the area of ADL, mobile learning, and defense and security education. The insights presented by the contributions are based in research projects that are closely related to the educational practices of security and defense organizations. The previous findings already indicated that the core technological concepts are well understood and are ready for mobile learning applications. However, security and defense organizations face three key challenges for implementing mobile learning:

- Organizational regulations

- Interoperability of mobile learning solutions

- Novel approaches to educational design.

The importance of laws and organizational regulations in the security and defense sector cannot be underestimated. In order to bring mobile learning solutions from prototypes to practice, it is necessary to understand the context in which mobile learning will be applied. Specifically, defense organizations have rigid rules for how and where to use mobile devices. These rules go far beyond the level of research ethics. In their article, Jacob Hodges and Geoff Stead emphasize the need for better knowledge about how organizational, national, and international regulations influence the introduction of new educational technologies and approaches in security and defense organizations.

Integrating mobile learning with existing infrastructures is the primary challenge confronting the effort to scale up the use of mobile devices for education and training. This not only includes the user interfaces of mobile devices, but also touches on the interoperability of mobile learning solutions. Christian Glahn's essay analyzes how organizations can leverage their existing educational resources to support mobile learn-

2 Christian Glahn, ed., "Workshop Proceedings: Mobile Learning in Security and Defense Organizations," Proceedings of the $11^{\text {th }}$ World Conference on Mobile and Contextual Learning, ed. Jari Multisala, Marcus Specht, and Mike Sharples (Helsinki, 21-24 October 2012); available at http://ceur-ws.org/Vol-955/workshops/WS6Security.pdf. 
ing. The approach outlined in this article aims at lowering the barriers to the introduction of mobile learning through the use of SCORM-compliant learning material that is already present in many organizations. Kristy Murray and her associates go a step further, and provide an outlook into the future of SCORM by showing the relation of the Experience API (xAPI) and mobile learning.

Finally, it has become evident that mobile learning also requires revisiting the instructional design concepts for ADL. This is not only required for novel concepts such as mobile collaborative simulations, but also for more conventional concepts such as formative tests and content delivery. Stefaan Ternier and his colleagues in their article introduce the ARLearn framework for creating location-based and context-aware simulations for teams in real-world settings. This framework has been used for security training at the United Nations Refugee Agency (UNHCR) in order to provide an authentic learning experience. Glahn's approach applies the instructional design concepts of micro learning and learning analytics to increase the continuity of learning of mobile learners. An initial proof of concept of this concept analyzed the implications of reusing existing training materials in new mobile instructional designs.

The articles in this issue provide a comprehensive overview of current findings and developments in the area of mobile learning in security and defense organizations. The authors address the key challenges and provide suggestions as well as solutions that provide a foundation for developing best practices of using mobile technologies in education and training. 
THE QUARTERLY JOURNAL

\section{Bibliography}

Glahn, Christian. "Workshop Proceedings: Mobile Learning in Security and Defense Organizations(link is external)." In 11th World Conference on Mobile and Contextual Learning. Helsinki, 2012.

Marcotte, Ethan. Responsive Web Design(link is external). A List Apart (alistapart.com), 2010. 